\title{
Persistence of solid fuel use despite increases in LPG ownership: New survey evidence from rural north India
}

Aashish Gupta, Sangita Vyas, Payal Hathi, Nazar Khalid, Nikhil Srivastav, Dean Spears, Diane Coffey

Solid fuel use is an important contributor to air pollution and disease burden in India. We present survey evidence documenting ownership of liquefied petroleum gas (LPG) and cooking fuel use in rural north India. LPG ownership increased dramatically from 2014 to 2018, substantially driven by the Ujjwala Yojana. Three-quarters of rural households in Bihar, Madhya Pradesh, Rajasthan, and Uttar Pradesh had LPG by 2018. Almost all of these households also had a stove that uses solid fuels, and among those owning both, almost three-quarters used solid fuels the day before the survey. Household economic status, relative costs of cooking fuels, gender inequality, and beliefs regarding the ease, food taste, and health impacts of cooking with solid fuels versus LPG were important contributors to high solid fuel use despite LPG ownership. Households that continue to use solid fuels continue to expose themselves and their neighbours to harmful air pollution. To realize the full health benefits of Ujjwala's expansion in LPG ownership, attention must now be turned towards discouraging the use of solid fuels and promoting exclusive use of LPG. This is an urgent priority for research, policy, and action.

Gupta, Khalid, Hathi, Srivastav, Vyas, Spears, and Coffey conduct research with r.i.c.e. Gupta is affiliated with Penn; Hathi with UC Berkeley; and Srivastav, Vyas, Spears, and Coffey with UTAustin. Spears is also Research Fellow at IZA and an Affiliated Researcher at IFFS. Aashish Gupta (aashishg@sas.upenn.edu; Population Studies Center, University of Pennsylvania, 239 McNeil Building, 3718 Locust Walk, Philadelphia, PA 19104-6298) and Sangita Vyas (sangita.vyas@utexas.edu; Department of Economics, University of Texas at Austin, 2225 Speedway, Austin, Texas 78712) are corresponding authors.

We thank Shilpa Bagde, Kailash Kumar, Amit Kumar, Laxmi Saini, and Poonam Saini for their help in conducting the fieldwork. This is a preprint version. The paper was published in volume 55 issue 3 (Jan 18, 2020) of the Economic and Political Weekly. The published version is available at https://www.epw.in/journal/2020/3/special-articles/persistence-solid-fuel-userural-north-india.html 


\section{Introduction}

Exposure to air pollution has important consequences for public health. A major source of air pollution exposure in rural India is the use of solid fuels, such as dung cakes and wood, for cooking and heating. In the National Family Health Survey (NFHS) 2015-2016, 75\% of rural Indian households reported mainly using solid fuels for cooking. High levels of indoor air pollution can kill infants, get in the way of healthy child development, and contribute to heart and lung disease (Smith 2000). There are also important externalities associated with cooking with solid fuels (Salvi and Barnes 2009). Lung function is worse on average among women who cook with solid fuels, but lung function for all adults is worse in villages in which a greater fraction of households cook with solid fuels (Gupta 2018).

In May 2016, the Indian government launched the Pradhan Mantri Ujjwala Yojana, which aims to promote the use of clean cooking fuel in rural India. The scheme subsidizes liquified petroleum gas (LPG) connections for rural households by providing a free gas cylinder, regulator, and pipe. ${ }^{1}$ Reducing the use of solid fuels is an important public health goal because it would reduce exposure to harmful indoor air pollution. The central government claimed that by December 2018, 6 crore households had received access to LPG through the Ujjwala Yojana, and that $90 \%$ of all Indian households owned an LPG cylinder and stove (Government of India 2019).

How successful have these government initiatives been in reducing solid fuel use in rural India? This article addresses this question using data from a 2018 survey on fuel use which revisited households originally interviewed in 2014 in rural Bihar, Madhya Pradesh, Rajasthan, and Uttar Pradesh. These states, which we will refer to collectively as the "sample states," are important to study in the context of fuel use because they represent over two-fifths of India's rural population, and have been slower to adopt clean cooking fuels than other rural parts of India.

Ujjwala has led to a substantial increase in LPG ownership among rural households in the sample states. About three-quarters of households reported owning LPG at the time of the survey, up from about one-third in 2014. This is an important improvement. However, we also find that many LPG owners, and particularly those that received cylinders through Ujjwala, still use solid fuels to cook. Most LPG owners also own a stove that uses solid fuel, and among households owning both, about three-quarters of households used solid fuels the day before the survey. $37 \%$ used both LPG and solid fuels, and 36\% cooked everything using solid fuels.

Although the Ujjwala Yojana has substantially increased access to LPG, many households that have LPG continue to use solid fuels. These household behaviours have important implications for the potential health impacts of Ujjwala. Households that continue to use solid fuels 
continue to expose themselves and their neighbours to harmful air pollution. Discouraging the use of solid fuels and promoting exclusive LPG use will be essential to realizing the full health benefits of the expansion in LPG ownership brought about by Ujjwala.

What contributes to such high solid fuel use among LPG owners? We investigate the contributions of four factors: household wealth; costs of alternative cooking fuels; gender inequalities in household tasks; and beliefs regarding ease, food taste, and health impacts, of using solid fuels versus LPG. We find evidence that all four factors contribute to continued solid fuel use among LPG owners.

Households with more assets were more likely to have exclusively used LPG to cook the day before the survey compared to households with fewer assets. However, most of the richest households that owned LPG still used solid fuels to cook at least one item the day before the survey. Most households make and collect solid fuels on their own, rather than buy them. Thus, refilling an LPG cylinder is monetarily more expensive than alternative fuel options, particularly for households that have animals, land, or who live near wooded areas. Moreover, women do the majority of the work involved in making and cooking with solid fuels. Therefore, household members that are most likely to handle solid fuels are often not economic decision-makers and often do not work for pay outside the home. Our fieldwork suggests that families do not perceive the opportunity cost of this time while considering which fuels to use. Beliefs and attitudes also play a role. Even though most people believe that cooking on gas is easier and less harmful to the health of the cook, most also believe that food cooked using solid fuels is better for the health of those eating the food, and is tastier.

To substantially reduce solid fuel use in rural north India, attention will now need to turn from increasing LPG ownership to increasing its exclusive use. The factors described above are likely among the explanations for why households still use solid fuels to cook, despite having LPG. Determining strategies for successfully promoting exclusive LPG use among owners is an important avenue for further research. Potential avenues to explore include larger subsidies for cylinder refills, informational campaigns that educate about the harms of air pollution exposure, and behavioural campaigns that change attitudes.

These findings also suggest that timely and disaggregated administrative data on refills are essential to monitoring the progress of Ujjwala in reducing solid fuel use. These data provide a direct indication of usage. Now that a substantial fraction of rural households have LPG, efforts must be made to track use. 


\section{Methods}

\subsection{Quantitative data}

The quantitative analyses in this paper draw on data from a panel survey which visited households in 2014 and 2018 in 11 districts in rural north India: three districts in each of Bihar, Madhya Pradesh, and Uttar Pradesh, and two districts in Rajasthan. Villages were randomly drawn using proportional-to-size sampling taken from the Government of India's District Level Health Survey, and households were randomly selected using an in-field randomization procedure. A description of the sampling strategy for the original sample of villages and households can be found in Coffey et al. (2014).

Table 1 summarizes the number of villages and households visited in each state in $2018 .^{2}$ Among the households first interviewed in 2014 that we attempted to re-interview in 2018, $88 \%$ were successfully re-interviewed. The 2018 survey also included some new households; about one-fifth of households were first interviewed in 2018. Gupta et al. (2018) discusses the sampling strategy for new households in the 2018 survey.

Table 1: Sample households and villages

\begin{tabular}{lccccc}
\hline & $\begin{array}{c}\text { Sample } \\
\text { States }\end{array}$ & Bihar & $\begin{array}{c}\text { Madhya } \\
\text { Pradesh }\end{array}$ & Rajasthan & $\begin{array}{c}\text { Uttar } \\
\text { Pradesh }\end{array}$ \\
\cline { 2 - 6 } households & 1,550 & 367 & 459 & 241 & 483 \\
$\quad$ in 2014 sample & 1,216 & 293 & 347 & 172 & 404 \\
not in 2014 sample & 334 & 74 & 112 & 69 & 79 \\
villages & 127 & 30 & 38 & 27 & 32 \\
\hline
\end{tabular}

Both surveys captured LPG ownership by households, but the 2018 survey included additional modules on fuel use and cooking, including: the fuels used for yesterday's cooking, expenditure on cooking fuels, who cooks and makes or collects solid fuels, and attitudes towards cooking with LPG and solid fuels. Following the terminology used by our respondents, we refer to traditional stoves that use solid fuels simply by "chulha," and to stoves that use LPG by "LPG," or "gas."

All statistics that we present in this paper use sample weights constructed based on the 2011 Census of India. Individuals in our sample are reweighted based on the state they live in, age, and sex, to be representative of the rural population in the sample states. Household weights are constructed by summing the weights of all individuals in the household. The questionnaires, 
datasets, and Stata dofiles, can be accessed here: https://riceinstitute.org/data/2014-and2018-rural-sanitation-surveys/.

\subsection{Qualitative data}

This paper also draws on qualitative field work conducted in Reusa block of Sitapur district, Uttar Pradesh, in January 2017. We conducted 29 in-depth, semi-structured interviews in five randomly-selected villages in the block. We interviewed randomly-selected households and a representative from Indane, one of the agencies implementing the Ujjwala Yojana. The interviews focused on understanding the activities that contribute to air pollution and how the policies that aim to mitigate these activities are implemented and perceived in the rural context. We also conducted qualitative interviews with local actors involved in the implementation of Ujjwala in villages visited during the quantitative survey. These interviews inform the interpretation of our quantitative findings.

\section{Patterns and trends in LPG use and ownership}

Figure 1: Slow adoption of clean cooking fuels in rural households in the sample states

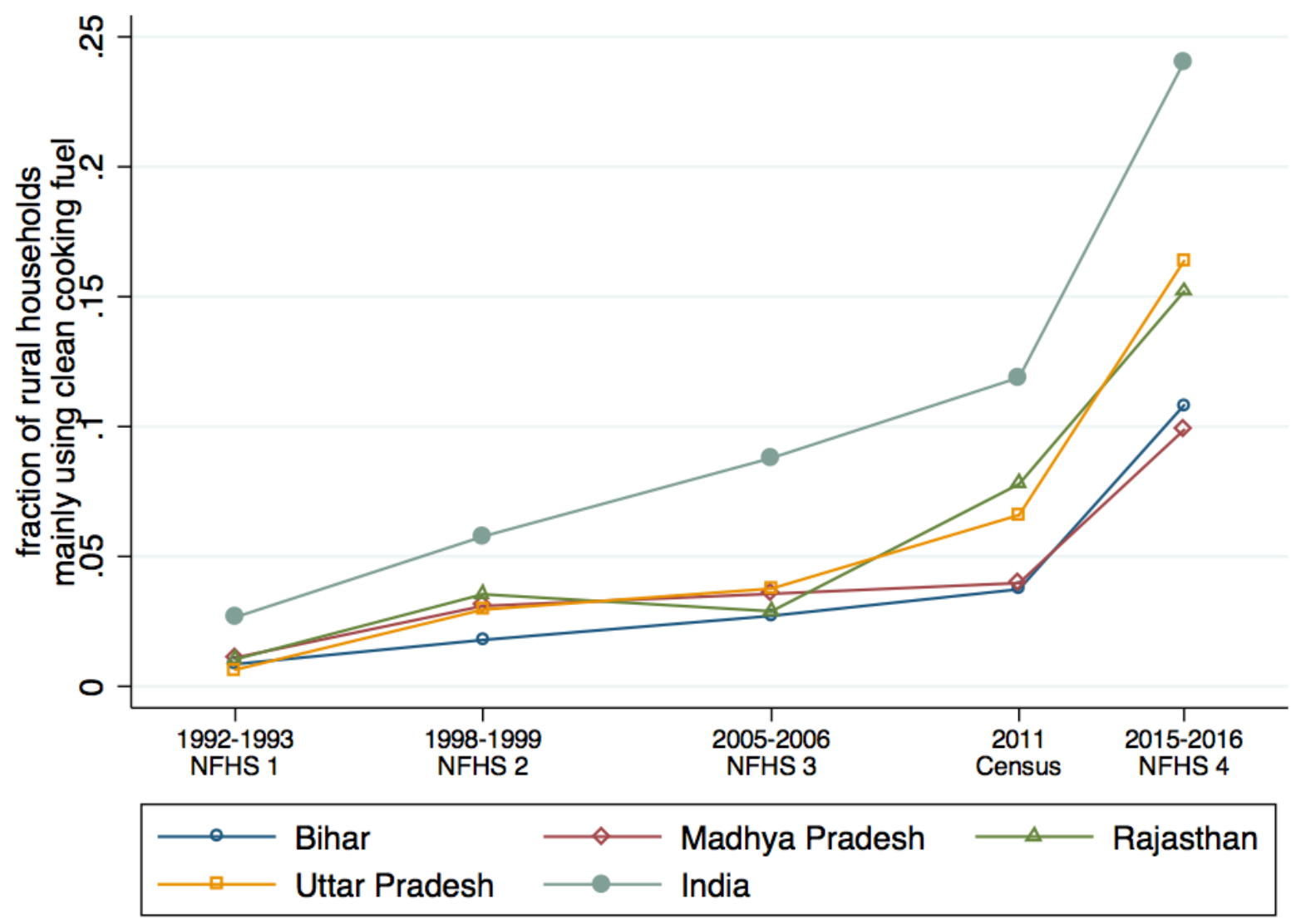


Figure 1 shows trends in the fraction of rural households that mainly use a clean fuel source for cooking, including LPG, electricity, and biogas from the NFHS and the 2011 Census. Each of the four states visited in the 2018 survey are shown separately, in addition to rural India as a whole. Since 2005, and especially since 2011, households in the sample states began adopting LPG for cooking. However, compared to other rural parts of India, a smaller fraction of rural households in the sample states report mainly using a clean fuel source.

Are rates of usage of clean cooking fuel low in the sample states because households do not have LPG? Panel A of Table 2 presents estimates of LPG ownership in 2014 and 2018 based on the two surveys discussed in section 2.1. In 2014, 32\% of households in the sample states had LPG. However, Panel B shows that among households that had LPG in 2014, most of them mainly used wood or dung cakes for cooking. Only about one-quarter of LPG owners in the sample states reported mainly using LPG for cooking. ${ }^{3}$ This statistic suggests that low reported usage of clean fuels cannot be fully explained by low rates of ownership of LPG.

Panel A also shows that LPG ownership significantly increased between 2014 and 2018. By 2018, 76\% of rural households in the sample states had LPG. In Panel C of Table 2, we show that among households that did not own LPG in $2014,69 \%$ had it by 2018 , and about $59 \%$ received it from the government through the Ujjwala Yojana.

Table 2: LPG and chulha ownership in 2014 and 2018: Substantial increase in LPG ownership

\begin{tabular}{crrrrr}
\hline & $\begin{array}{c}\text { Sample } \\
\text { States }\end{array}$ & \multicolumn{1}{c}{$\begin{array}{c}\text { Madhya } \\
\text { Bihar }\end{array}$} & $\begin{array}{c}\text { Uadesh } \\
\text { Pradtar }\end{array}$ & $\begin{array}{c}\text { Uttan } \\
\text { Pradesh }\end{array}$ \\
\cline { 2 - 6 } Panel A: all households & & & & & \\
own LPG, 2014 & $32.0 \%$ & $29.0 \%$ & $19.6 \%$ & $52.3 \%$ & $31.3 \%$ \\
own LPG, 2018 & $76.2 \%$ & $71.2 \%$ & $71.2 \%$ & $89.2 \%$ & $76.6 \%$ \\
own chulha, 2014 & $98.8 \%$ & $98.0 \%$ & $99.8 \%$ & $98.2 \%$ & $99.0 \%$ \\
own chulha, 2018 & $98.6 \%$ & $100.0 \%$ & $98.8 \%$ & $98.6 \%$ & $97.8 \%$
\end{tabular}

Panel B: households that own LPG in 2014

$\begin{array}{llllll}\text { mainly use solid fuels for cooking } & 78.1 \% & 82.4 \% & 85.4 \% & 83.3 \% & 72.6 \%\end{array}$

Panel C: households that did not own LPG in 2014

$\begin{array}{llllll}\text { owns LPG, } 2018 & 69.3 \% & 67.9 \% & 67.1 \% & 83.5 \% & 67.9 \% \\ \text { received from government } & 58.7 \% & 63.1 \% & 65.5 \% & 56.2 \% & 54.1 \%\end{array}$

Panel D: households that own LPG in 2018

$\begin{array}{llllll}\text { received from government } & 43.0 \% & 49.2 \% & 59.0 \% & 32.6 \% & 38.5 \%\end{array}$

\begin{tabular}{llllll} 
also owns chulha & $98.2 \%$ & $100.0 \%$ & $98.5 \%$ & $98.5 \%$ & $97.1 \%$ \\
\hline
\end{tabular}

Note: Estimates use sample weights. Source: 2014 and 2018 Surveys. 
These statistics show that Ujjwala contributed to a large increase in ownership of LPG in the sample states. It is also notable that the penetration of the programme was greater in Madhya Pradesh, which had the lowest coverage of LPG in 2014. It is important to observe, however, that at least some of the households that received LPG through Ujjwala likely would have gotten it on their own in the absence of the programme. ${ }^{4}$

Figure 2: In sample states in 2018, poorer households are less likely to have LPG, and more likely to have gotten LPG through Ujjwala

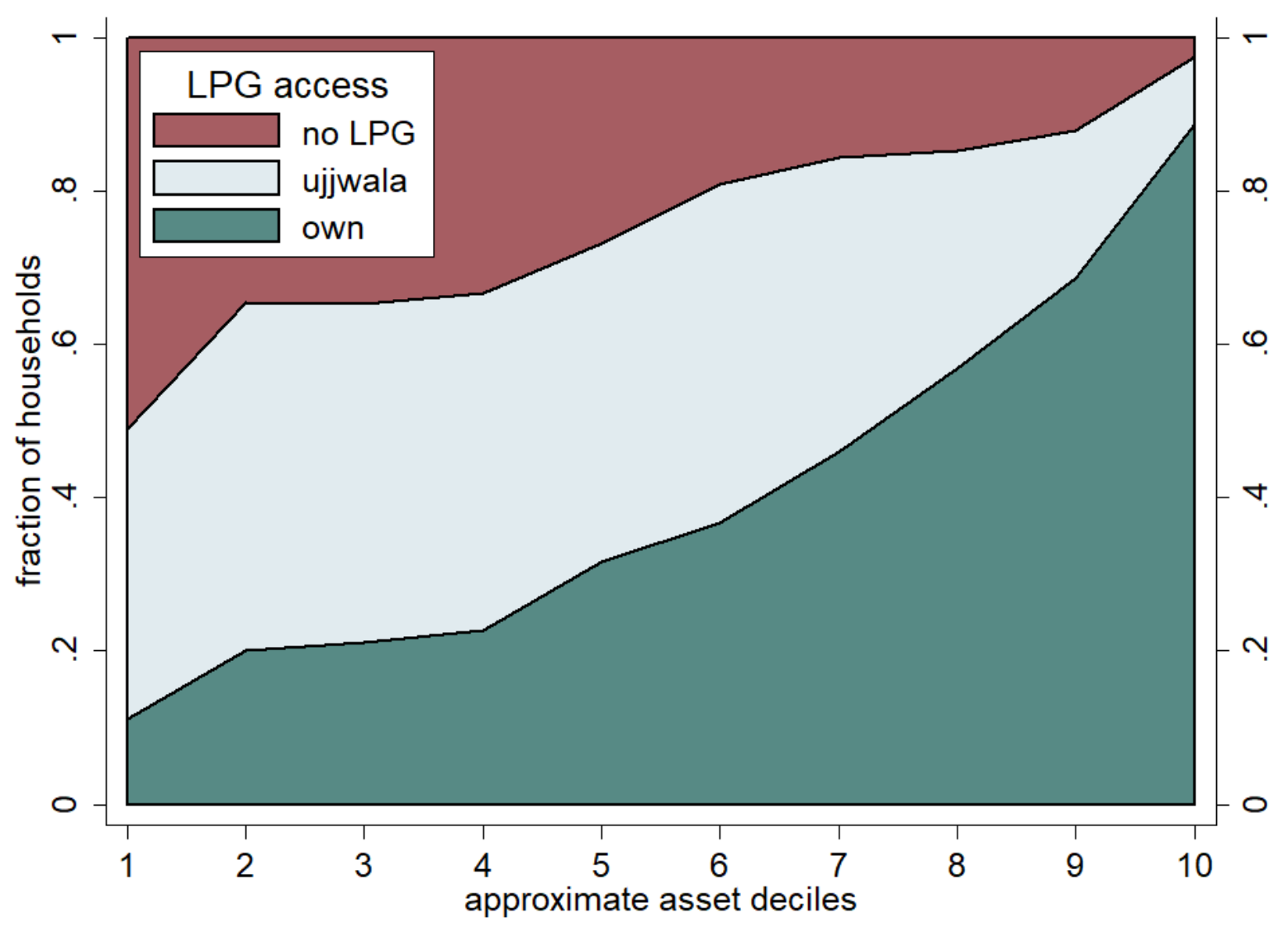

Note: Estimates use sample weights. Source: 2018 Survey of Rural Sanitation and Solid Fuel Use.

Figure 2 shows the fraction of households in 2018 that got LPG on their own, received LPG from the government through Ujjwala, and did not have LPG, at every level of asset wealth. ${ }^{5}$ Households in asset decile one are the poorest. Poor households are less likely to have LPG than rich households, but poor households are more likely to have received LPG through Ujjwala. Looking at households who have gotten LPG on their own, LPG ownership follows a steep asset gradient: poor households are much less likely to have gotten LPG on their own compared to rich households. Ujjwala has flattened but not eliminated this gradient. According to the programme guidelines, the scheme identifies beneficiary households based on indicators 
of deprivation identified from the 2011 Socio-Economic Caste Census. However, although Ujjwala has more often provided cylinders to poorer households, many poor households have still been left out.

\section{Many LPG owners still use solid fuels}

What has been the impact on household fuel use of the large expansion in access to LPG in rural north India? The patterns of usage in 2014 showed that many households mainly used solid fuels despite having LPG. However, statistics on usual use miss patterns of fuel mixing that are nevertheless important for understanding potential health impacts, and the transition from solid to clean fuel use in rural India. To better understand how households integrate LPG into their cooking fuel options, we introduced a series of questions to the 2018 survey that specifically addresses fuel mixing. This module improves on prior surveys investigating fuel use by specifically capturing daily fuel mixing. We provide the first evidence, to our knowledge, of the fraction of households that use multiple fuel sources on a daily basis. ${ }^{6}$

Table 2 shows that $98 \%$ of households with LPG also had chulha, already indicating continued solid fuel use among LPG owners. For households that owned both LPG and chulha, we asked a female adult in the household whether the following foods, one-by-one, were cooked in the household the day before the survey: roti (flatbread), rice, sabzi (vegetable), daal (lentils), chai (tea), and milk. For each item that was cooked the day before the survey, we asked whether it was cooked on chulha, or on gas. If the respondent reported cooking a food item on chulha at one time during the day and on LPG at another time, we recorded the household as using both.

Table 3 reports on the answers to these questions. Despite having LPG, many households used chulha to make food the day before the survey. Some food items were more commonly made on chulha, while others were more often cooked on LPG. For example, among households that made chai, most made it on LPG. In contrast, among those who made roti, most made them on chulha.

In our qualitative work, we learned some of the reasons for these differences. One woman, a teacher in a private school, explained: "Everyone says that on gas the roti remains raw, it does not cook properly. Instead, if you cook it in chulha, the heat in there cooks it slowly and fully." Several respondents also told us they make chai on LPG because it takes less time than chulha, and so can be served to guests quickly.

Only $27 \%$ of households reported exclusively using LPG to cook all the items, of these six, that they made the day before the survey. $37 \%$ reported making some items on LPG and some on chulha, and $36 \%$ made everything on chulha. 
Households that received LPG through the Ujjwala Yojana were less likely to use it exclusively than those who did not. They were also more likely to use chulha exclusively. There could be several reasons for this. Ujjwala beneficiaries are poorer, on average, than households who got LPG on their own, and refilling the cylinder is a greater fraction of their monthly consumption. It may also be the case that households that got LPG on their own have higher demand for using LPG than households who got it through Ujjwala.

These findings suggest that the majority of households owning LPG either mix fuels or still exclusively use chulha, and this is particularly true for households that received LPG through Ujjwala. The fact that many rural households mix fuel sources helps make sense of slow improvements in the fraction of households mainly using clean fuels for cooking reported in nationally-representative surveys.

Table 3: Fuel used yesterday for cooking six food items, among households owning LPG and chulha

\begin{tabular}{|c|c|c|c|c|}
\hline \multirow[b]{2}{*}{ Panel A } & \multirow{2}{*}{$\begin{array}{c}\text { cooked } \\
\text { yesterday }\end{array}$} & \multicolumn{3}{|c|}{ if cooked yesterday, used } \\
\hline & & LPG & chulha & both \\
\hline roti & $96.0 \%$ & $32.1 \%$ & $62.5 \%$ & $5.4 \%$ \\
\hline rice & $76.6 \%$ & $42.4 \%$ & $55.3 \%$ & $2.3 \%$ \\
\hline sabzi & $94.9 \%$ & $39.2 \%$ & $58.9 \%$ & $2.0 \%$ \\
\hline daal & $65.8 \%$ & $44.5 \%$ & $55.0 \%$ & $0.5 \%$ \\
\hline chai & $92.2 \%$ & $61.1 \%$ & $36.8 \%$ & $2.2 \%$ \\
\hline \multirow[t]{2}{*}{ milk } & $81.6 \%$ & $48.1 \%$ & $49.7 \%$ & $2.2 \%$ \\
\hline & & \multicolumn{3}{|c|}{ cooked all items yesterday on } \\
\hline \multicolumn{2}{|l|}{ Panel B } & LPG & chulha & both \\
\hline \multicolumn{2}{|l|}{ Sample States } & $27.0 \%$ & $36.0 \%$ & $37.0 \%$ \\
\hline \multicolumn{2}{|l|}{ Bihar } & $26.2 \%$ & $42.7 \%$ & $31.1 \%$ \\
\hline \multicolumn{2}{|l|}{ Uttar Pradesh } & $33.1 \%$ & $39.3 \%$ & $27.6 \%$ \\
\hline \multicolumn{2}{|l|}{ Madhya Pradesh } & $22.6 \%$ & $33.8 \%$ & $43.4 \%$ \\
\hline \multicolumn{2}{|l|}{ Rajasthan } & $16.0 \%$ & $19.4 \%$ & $64.7 \%$ \\
\hline \multicolumn{2}{|c|}{$\begin{array}{l}\text { conditional on receiving LPG from govt, cooked } \\
\text { all items yesterday on }\end{array}$} & $15.2 \%$ & $52.8 \%$ & $32.0 \%$ \\
\hline
\end{tabular}




\section{What contributes to solid fuel use among LPG owners?}

\subsection{Household wealth}

Do so many rural LPG owners use solid fuels because they are poor? Refilling a cylinder costs almost half the average monthly per-capita expenditure in rural India (National Sample Survey Organization 2013), and if used exclusively, the average rural household would likely go through a cylinder each month (Dabadge et al. 2018). It's possible that poor households do not refill their cylinders often because of the expense.

Figure 3 provides evidence that household economic status may be part of the reason why households mix fuel sources, but it is certainly not the only one. It plots the fraction of households that only used chulha, only used LPG, and used both fuel sources to cook food the day before the survey, at every level of asset wealth. Only households that have both LPG and chulha are summarized in this figure.

\section{Figure 3: Substantial chulha use yesterday among households owning LPG}

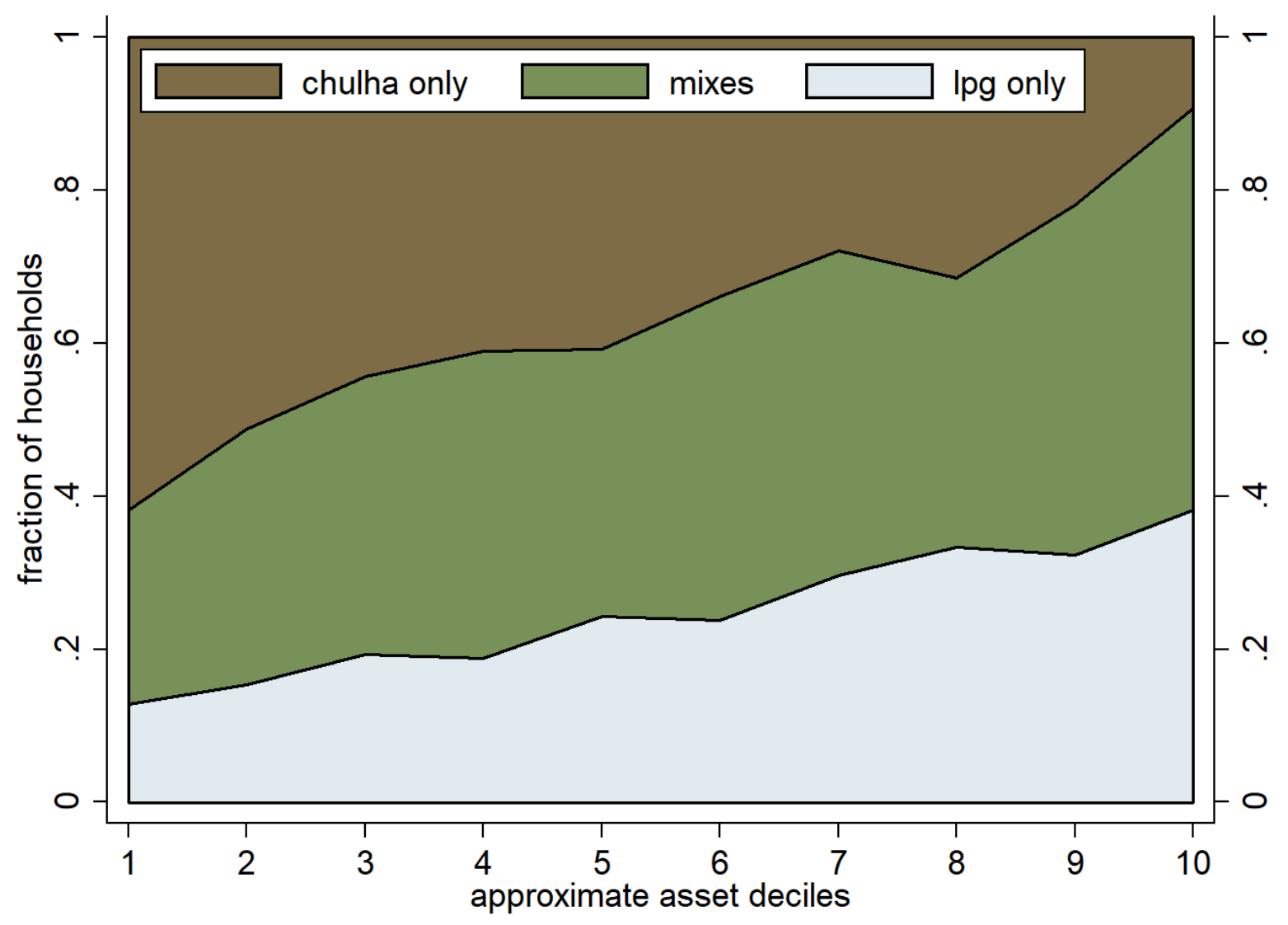

Note: Estimates use sample weights. Source: 2018 Survey of Rural Sanitation and Solid Fuel Use. 
Conditional on having both types of fuel sources, rich households are less likely to exclusively use chulha, and more likely to exclusively use LPG, than poor households. However, notably, less than $37 \%$ of the richest households exclusively use LPG conditional on having it. Interestingly, rich households are more likely to mix fuel sources than poor households. About $47 \%$ of the richest LPG-owning households mixed fuel sources the day before the survey. The main finding from this figure is that among households that have LPG, richer households are more likely to use it compared to poorer household, but most of these rich households still use chulha on a daily basis.

\subsection{Easy availability of other fuel sources}

For many rural households in the sample states, solid fuels are easily available and free of cost. Households that own cows or buffalos have access to dung to make dung cakes, and those that own land can use its agricultural waste or cut branches from the trees growing on it. Public land and forests are also a source of free wood. Table 4 shows that among households that have chulha, which is almost all households, $68 \%$ report exclusively making or collecting solid fuels on their own, and $24 \%$ report making or collecting some solid fuels on their own, and buying some. Because so many households do not buy solid fuels for regular use, the median cost per month for dung or wood among all households that have chulha is Rs. 0 , and the mean is Rs. 214. Among households that buy solid fuels for regular use, the mean cost per month is Rs. 737. ${ }^{7}$

Some of the households that are part of this calculation also have and use LPG, and therefore have lower solid fuel costs than if they did not have LPG at all. Therefore, we also look at solid fuel costs among households that buy solid fuels, and do not have LPG. For these households, the mean cost per month is Rs. 840 .

In comparison, among households reporting they had refilled their cylinder at least once, the mean reported cost of a cylinder refill is Rs. 876. Of course, some households receive the LPG subsidy in their bank accounts. Among households that have an LPG cylinder, 51\% reported receiving the subsidy, and $13 \%$ reported sometimes receiving the subsidy. Not all respondents knew the last subsidy amount, but those that did reported receiving almost Rs. 300, on average. Therefore, for these households, the average net cost of one LPG refill was around Rs. 600.

We also find that $35 \%$ of all LPG-owning households, and $60 \%$ of households that received LPG through Ujjwala, report not receiving the subsidy at all. Under Ujjwala, the government provides a gas cylinder, regulator, and pipe for free, and gives loans to households for the stove and the gas in the first cylinder. Over time, these loans are supposed to be paid back incrementally as beneficiary households pay the total unsubsidized rate for refills until the loan 
is paid off. Depending on the subsidy amount, it can take several refills for the loan to be paid off. This means that the cost of using LPG for Ujjwala beneficiaries is higher than for non-

Ujjwala households, and could be part of the reason why Ujjwala households are less likely to have used LPG exclusively to cook food the day before the survey. Most households were not aware that they would not receive subsidies in their account until the 'loan component' of the Ujjwala scheme had been adjusted against their subsidies. Additionally, many households were not aware of the bank account their subsidy was being transferred to. ${ }^{8}$

Table 4: Fuel costs, usage patterns, and Ujjwala subsidies

Panel A: households that have chulha

A.1 solid fuel access

do not use dung or wood (\%)

make or collect dung or wood (\%)

68.0

make or collect and buy dung or wood (\%)

23.5

buy dung or wood, do not make or collect (\%)

A. 2 solid fuel costs

unconditional mean cost per month of dung and wood (Rs.)

conditional on buying dung or wood, mean cost per month (Rs.)

737

conditional on not having LPG and buying dung or wood, mean cost per month (Rs.)

840

Panel B: households that have LPG

B.1 LPG cylinder use

mean time cylinder lasts (months)

conditional on exclusive use yesterday, mean time cylinder lasts (months)

2.5

conditional on having cylinder, have ever refilled cylinder (\%)

90.9

B.2 get subsidies

yes (\%)

50.8

no $(\%)$

sometimes (\%)

13.4

don't know (\%)

B.3 LPG cylinder costs

conditional on refilling cylinder, mean cost of last refill (Rs.)

B.4 mean subsidy amount conditional on getting subsidy and knowing amount (Rs.)

Note: Estimates use sample weights. Source: 2018 Survey of Rural Sanitation and Solid Fuel Use.

The relative cost of different fuel sources is likely a reason for some households to continue to use solid fuels, despite having LPG. If used regularly, one cylinder would likely last a household with five members about one month (Dabadge et al. 2018). For most households, solid fuels are free. For the minority of households that do buy solid fuels, the monthly cost of unsubsidized 
LPG is about equal to the mean cost of solid fuels. It is only for the small minority of households who buy solid fuels and receive Ujjwala subsidies that an LPG cylinder is cheaper than solid fuels, on average.

\subsection{Gender inequality in household tasks}

Figure 4: Gender and age inequalities in cooking and collecting solid fuels
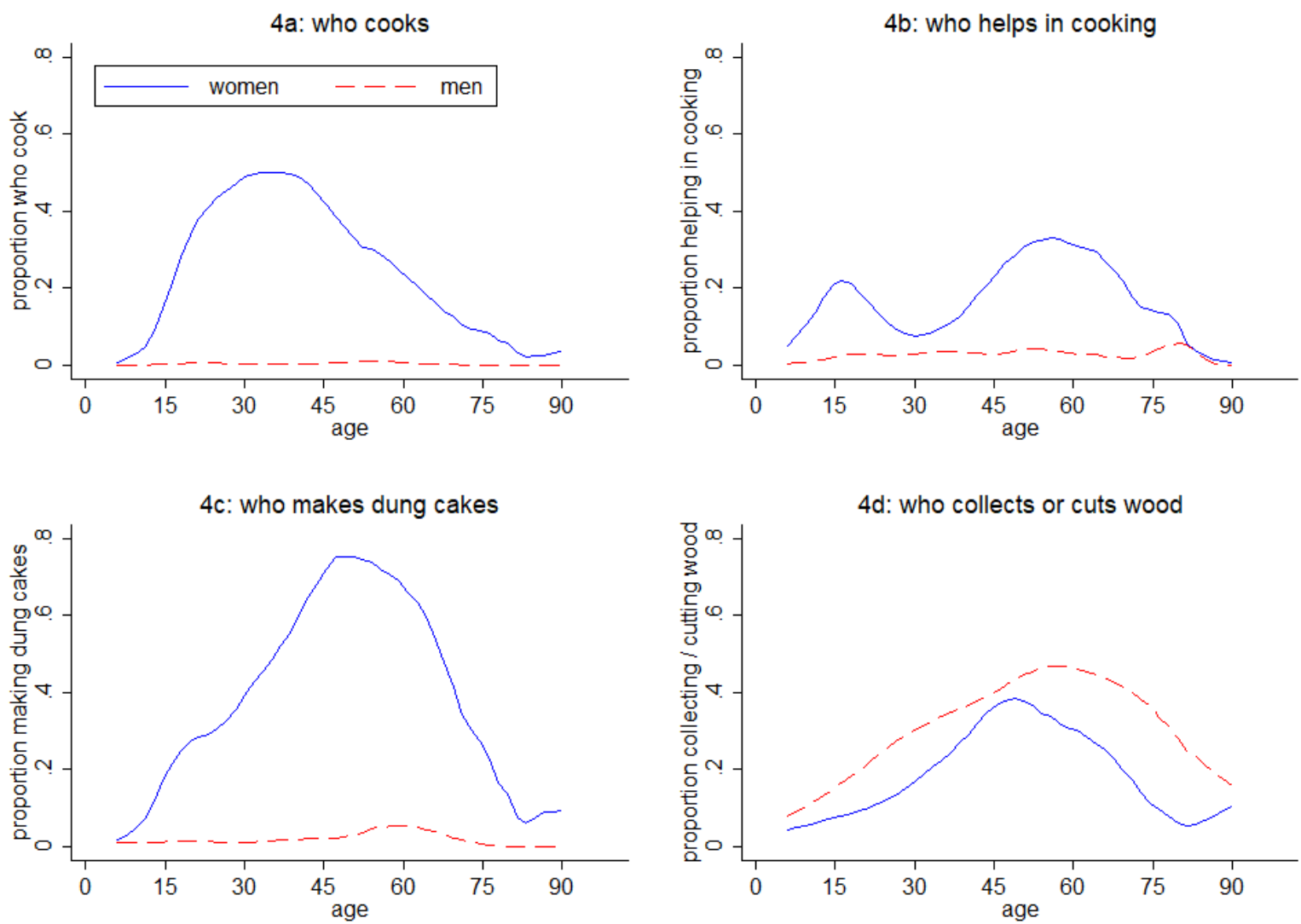

Note: Estimates use sample weights. Source: 2018 Survey of Rural Sanitation and Solid Fuel Use.

Figure 4 shows the proportion of men and women at each age who cook, help in cooking, make dung cakes, and cut and collect wood. At all ages, women are more likely to be the main cooks, and to help in cooking, than men. Women between the ages of 25 and 40 are the most likely to be the main cooks, and girls and older women are the most likely to help in cooking. Women are also much more likely to make dung cakes than men, with older women being the most likely to do this work. ${ }^{9}$ In contrast, men are slightly more likely to cut and collect wood than women. Women are more likely to work on dung than wood partly because of restrictions on movement. Still, many women are involved in the work of cutting and collecting wood, with middle-aged women being more likely to than younger women. Although we did not ask this separately in our survey, our field experience suggests that men are more likely to cut wood 
because they are more likely to use axes, and women are more likely to collect and carry it than men. ${ }^{10}$

It is evident from this figure that a large fraction of the work of cooking with solid fuels is performed by women. ${ }^{11}$ This may hinder greater LPG use in several ways. Since north Indian cultural norms discourage women from working for pay outside of the home, there is a low opportunity cost of time spent making and collecting solid fuels, and cooking on chulha. Also, men are required for picking up cylinder refills, since it is uncommon for households in rural areas to receive LPG deliveries at their doorstep. ${ }^{12}$ Women also have low status and are typically not economic decision-makers in the household (Das Gupta 1995). This is especially true for newly married and younger women, who are more likely to be the main cooks in the household. ${ }^{13}$ These factors likely contribute to the use of solid fuels, even among households that own LPG.

\subsection{Beliefs and attitudes}

In the 2018 survey, we also asked respondents a series of questions about their beliefs towards cooking with gas and chulha. These questions were asked early in the survey, before asking questions about government programs, in order to limit social desirability bias. The questions we asked were:

- Which do you think is easier to cook with, a gas stove or a chulha, or is there no difference?

- Which do you think makes the food taste better - a gas stove or a chulha, or is there no difference?

- Which do you think is better for the health of a person who eats the food - food cooked on a gas stove or food cooked on a chulha, or is there no difference?

- If we talk about the health of the person making the food, what do you think - cooking food on a gas stove is better for the health of the person cooking, or cooking food on a chulha is better for the person cooking, or is there no difference?

The tabulation of responses is shown in Table 5. All households were asked these questions, regardless of having LPG. Although not shown in the table, the results are very similar if one analyses the sample of LPG owners separately from non-owners. Respondents for these questions were adult women.

Most respondents believe that, compared to chulha, gas is easier to cook on and is healthier for the person cooking. ${ }^{14}$ Yet, the vast majority of respondents also believe that food cooked on chulha is tastier, and is better for the health of the person eating. The same private school teacher who liked rotis cooked on a chulha explained her beliefs to us: "On the chulha, cooking 
something is a pain in the neck. It also takes more time. It is easier to cook on gas. But some men here say that the chulha is better than gas. Food gets cooked properly on chulha." In response to our question on which is better for the health of the person eating, many respondents said that "eating food cooked on gas causes gas [in the stomach]."

Table 5: Beliefs and attitudes about LPG and chulha

\begin{tabular}{lccc}
\hline & LPG & chulha & $\begin{array}{c}\text { no } \\
\text { difference }\end{array}$ \\
\cline { 2 - 4 } & & & \\
easier to cook on & $77.4 \%$ & $14.4 \%$ & $8.2 \%$ \\
food tastes better from & $3.3 \%$ & $92.2 \%$ & $4.4 \%$ \\
better for health of person eating & $4.9 \%$ & $86.4 \%$ & $8.7 \%$ \\
better for health of person cooking & $69.8 \%$ & $22.0 \%$ & $8.2 \%$ \\
\hline stimates use sample weights. Source: 2018 Survey of Rural Sanitation and Solid Fuel Use.
\end{tabular}

The answers to these questions suggest that many women knowingly sacrifice their own health believing that their choices are promoting the health of their children, husbands, and other family members. These statistics also show that there is little awareness of the health externalities of burning solid fuels. Although many women recognized that using chulha was worse than gas for their own health, and spoke of the chulha smoke burning their eyes and making them cough, they still believed that using the chulha was good for the health of their family members. This is not true, though, because their family members cannot escape the ambient air pollution caused by solid fuel use.

Figure 5 shows the fraction of households at each level of asset ownership that used solid fuels the day before the survey, conditional on the response to each of these four questions. At every level of asset ownership, respondents that believed cooking on LPG was at least as easy as on chulha, and that food cooked on LPG was at least as tasty and healthy for the eater as food cooked on chulha, were less likely to live in households that used solid fuels the day before the survey than respondents that believed the opposite. Notably, respondents who believed that cooking on LPG was at least as good for the person cooking, were no more or less likely to have cooked on chulha than those believing chulha is better. ${ }^{15}$

The beliefs that food cooked on chulha is healthier and tastier are likely a part of the reason why many households still use solid fuels despite having LPG. Taste in particular appears to be an important factor. About $50 \%$ of the richest households believing that food cooked on LPG is no less tasty than food cooked on chulha exclusively used LPG the day before the survey. This reflects a very small number of respondents, though - over $92 \%$ of respondents believed that food cooked on chulha is tastier. 
Figure 5: Relationship between using chulha yesterday and fuel use beliefs, by asset deciles
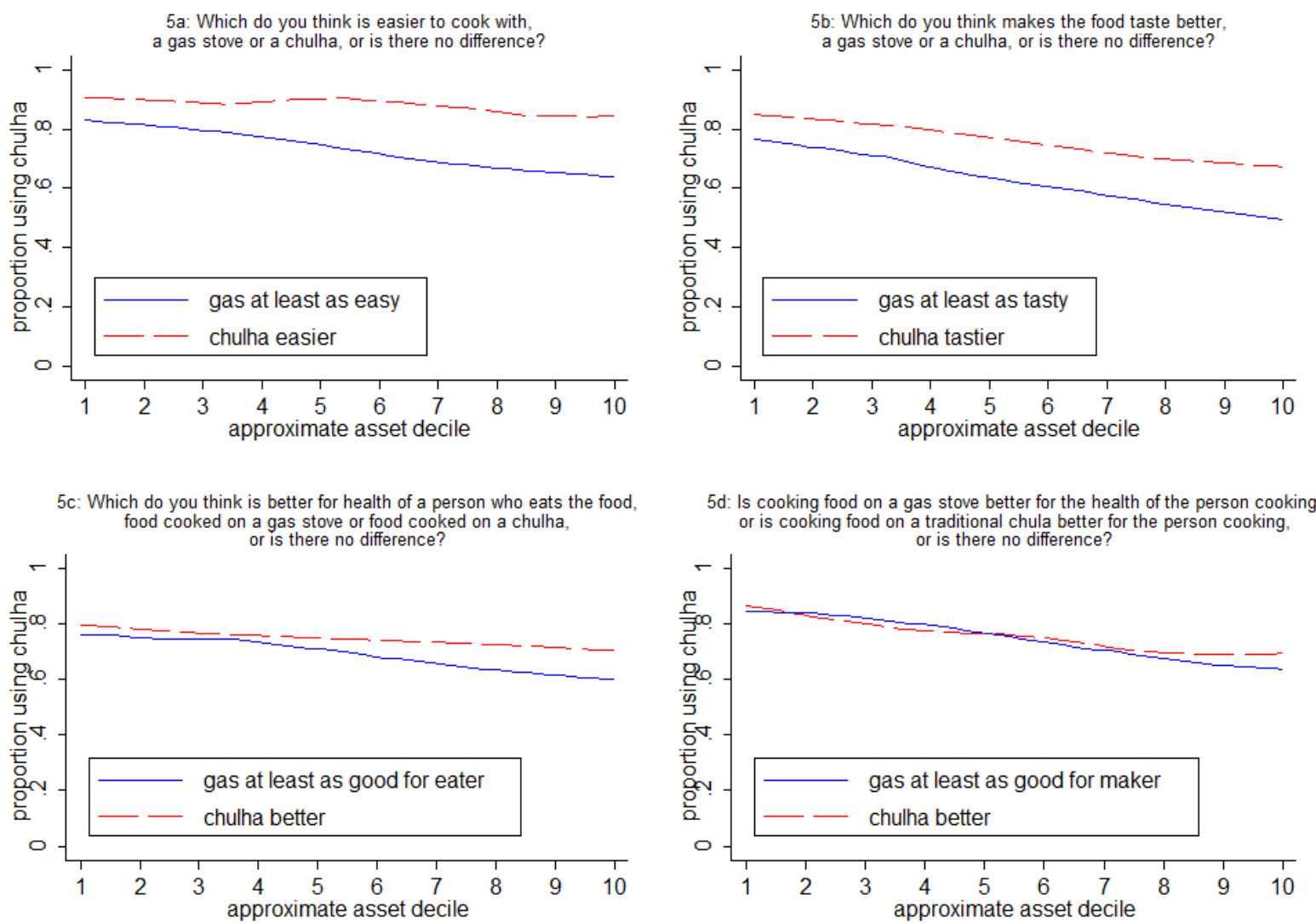

Note: Estimates use sample weights. Source: 2018 Survey of Rural Sanitation and Solid Fuel Use.

\section{Conclusion}

Despite the expansion in LPG ownership brought about by Ujjwala, most households still regularly cook with solid fuels. These findings have important implications for Ujjwala's effectiveness in reducing exposure to harmful indoor air pollution in rural India.

Discouraging the use of solid fuels, and promoting the exclusive use of LPG, will be essential for realizing health improvements. There are many important factors that contribute to cooking fuel decisions. These include household wealth; the availability and cost of different fuels; the status and decision-making power of the individuals who spend the most time making, collecting, and cooking with solid fuels; and beliefs and attitudes towards LPG versus chulha. Based on our findings, each of these factors likely contributes incrementally to continued solid fuel use. It's possible that other factors also contribute to solid fuel use despite LPG ownership.

Explaining solid fuel use despite LPG ownership, and designing interventions to discourage their use are important priorities for further research. Larger subsidies for cylinder refills, 
informational campaigns that educate about the harms of air pollution exposure, and behavioural campaigns that change attitudes, are three potential avenues worth exploring. Pillarisetti et al. (2019) report on a pilot study in rural Maharashtra testing free LPG refills, a monetary incentive to use LPG, and health messaging. More such studies should be conducted.

Advertisements currently promote Ujjwala by emphasising benefits to women. Although LPG use does benefit women, these advertisements reinforce women's roles as cooks. Instead, promoting men's involvement in household tasks such as cooking may help accelerate the use of LPG while promoting gender equality.

Our findings also suggest that monitoring the progress of Ujjwala requires monitoring cylinder refills (Dabadge et al. 2018). At the time we write this article, publicly available administrative data on Ujjwala is limited to the number of connections released in each state, at different points in time. Since so many households that have an LPG connection still regularly use solid fuels, this provides little indication of the extent to which LPG is being used. Disaggregated and regular data on refills are important to release because it helps directly measure use.

Ujjwala has made impressive achievements in expanding access to LPG in rural north India. However, many in this region continue to be exposed to harmful air pollution caused by the use of solid fuels for cooking. Attention now needs to be turned towards discouraging the use of solid fuels, and promoting exclusive use of LPG.

\section{References}

Anand, V. (2018). Two years of Ujjwala Yojana: Lack of awareness regarding benefits of LPG hinders scheme's objective at rural level. Firstpost, May 2018.

Brooks, N., Bhojvaid, V., Jeuland, M. A., Lewis, J. J., Patange, O., \& Pattanayak, S. K. (2016). How much do alternative cookstoves reduce biomass fuel use? Evidence from North India. Resource and Energy Economics, 43, 153-171.

Cheng, C. Y., \& Urpelainen, J. (2014). Fuel stacking in India: Changes in the cooking and lighting mix, 1987-2010. Energy, 76, 306-317.

Chattopadhyay, S.K., and Das, P. (2019). Running out of gas. Frontline, April 12.

Coffey, D., Gupta, A., Hathi, P., Khurana, N., Spears, D., Srivastav, N., \& Vyas, S. (2014). Revealed preference for open defecation. Economic \& Political Weekly, 49(38), 43.

Dabadge, A., Sreenivas, A., \& Josey, A. (2018). What Has the Pradhan Mantri Ujjwala Yojana Achieved So Far?. Economic \& Political Weekly, 53(20), 69. 
Das Gupta, M. (1995). Life course perspectives on women's autonomy and health outcomes. American Anthropologist, 97(3), 481-491.

Government of India (2019). Pradhan Mantri Ujjwala Yojana achieves 6 crore mark; Hon'ble Vice President hands over 6th crore connection to beneficiary. Press Information Bureau, 02 Jan 2019.

Gupta, A. (2018). Where there is smoke: Solid fuel externalities, gender, and adult respiratory health in India. Working paper.

Gupta, A., Khalid, N., Desphande, D., Hathi, P., Kapur, A., Srivastav, N., Vyas, S., Spears, D., \& Coffey, D. (2019). Changes in Open Defecation in Rural North India: 2014-2018. IZA discussion paper 12065.

Hirway, I., \& Jose, S. (2011). Understanding women's work using time-use statistics: The case of India. Feminist Economics, 17(4), 67-92.

Jain, A., Tripathi, S., Mani, S., Patnaik, S., Shahidi, T., and Ganesan, K. (2018). 'Access to Clean Cooking Energy and Electricity: Survey of States 2018'. CEEW.

Kishore, A., \& Spears, D. (2014). Having a son promotes clean cooking fuel use in urban India: Women's status and son preference. Economic Development and Cultural Change, 62(4), 673699.

Lahoti, R. (2016). Questioning the Phenomenal Success of Aadhaar-linked Direct Benefit Transfers for LPG. Economic and Political Weekly, 24.

Narayanan, N. (2019). The Modi Years: Are more Indians using cooking gas because of the Ujjwala scheme? Scroll.in

Pillarisetti, A. et al. (2019). Promoting LPG usage during pregnancy: A pilot study in rural Maharashtra, India. Environment international, 127, 540-549.

Salvi, S. S., \& Barnes, P. J. (2009). Chronic obstructive pulmonary disease in non-smokers. The Lancet, 374(9691), 733-743.

Sethi, N. and Deep, A. (2018). PMs plan for free gas connections is failing its objective as government had been warned it would. Scroll.in.

Sharma, K. (2018). Living with pain: Women's everyday lives and health in rural Bihar. The Hindu Center for Public Policy, Policy Report No. 23. 
Smith, K. R. (2000). National burden of disease in India from indoor air pollution. Proceedings of the National Academy of Sciences, 97(24), 13286-13293.

\footnotetext{
${ }^{1}$ Benefitting households have the option of getting an LPG stove and the cost of the first refill as a loan, adjusted against subsidy payments (see Narayanan 2019)

${ }^{2} \mathrm{~A}$ version of this table appeared in Gupta et al. (2018). The counts of households and villages are different in the two tables because Gupta et al. (2018) used an earlier version of the dataset that was partially cleaned. We use the final dataset in this study.

${ }^{3}$ In Panel B, we report the proportion of households that owned LPG in 2014 who report mainly using it. The question in the 2014 survey, similar to the census and NFHS surveys, was "What do you use most for cooking food?" The 2018 survey aimed to better estimate mixed use, and did not ask this question.

${ }^{4}$ These households would have had to pay initial costs of about Rs. 2000 for a stove and a cylinder, about Rs. 200 for the connection to the agency, and the cost of the first refill if they had gotten the connection on their own.

${ }^{5}$ In all figures that have assets on the horizontal axis, we use approximate asset deciles. We construct approximate asset deciles by first summing up the number of assets owned by each household, among 18 assets. We then sort the households into bins based on where they fall in the distribution of the number of assets owned. Households owning less than 7 assets are in bin 1 (11.7\% of households), owning 7 assets are in bin 2 (7.0\% of households), owning 8 assets are in bin 3 (8.6\% of households), owning 9 assets are in bin 4 (9.3\% of households), owning 10 assets are in bin 5 ( $8.9 \%$ of households), owning 11 assets are in bin 6 (9.4\% of households), owning 12 assets are in bin 7 (9.6\% of households), owning 13 assets are in bin 8 ( $8.4 \%$ of households), owing 14 or 15 assets are in bin 9 (13.5\% of households), and owning 16,17 or 18 assets are in bin 10 (13.6\% of all households).

${ }^{6}$ For example, Cheng and Urpelainen (2014) use multiple rounds of the NSS to show that over time, using multiple fuels for cooking has become more common. Jain et al. (2018) report findings from a panel survey in six states which is very similar to ours, documenting low exclusive LPG use. See also Brooks et al 2016.

${ }^{7}$ Costs per month are calculated from questions on how much was spent on the last dung or wood purchase, and how long the dung or wood would last.

${ }^{8}$ See also Lahoti 2016, Anand 2018, and Chattopadhyay and Das 2019.

${ }^{9}$ Sometimes older women said that their daughters or young daughters-in-law did not know how to make dung cakes properly.

${ }^{10}$ Ethnographic evidence supports this. Carrying wood and other loads on heads is also a cause for pains among women (Sharma 2018).

${ }^{11}$ For similar evidence from time use surveys, see Hirway and Jose (2011), and for ethnographic evidence, see Sharma (2018).

$1215.7 \%$ of respondents said that their last cylinder was delivered to their house. In some villages, delivery tempos go to the main road near villages on a fixed day on a month. In one village, a local shop used to serve as a delivery point - the local agency had kept filled cylinders at the shop and people could get a filled cylinder from the shopkeeper after paying him and depositing their own cylinder. However, most households had to go to the agency to collect a cylinder.

${ }^{13}$ Kishore and Spears (2014) find heterogeneity in the intrahousehold status of women based on the sex of their first child. Urban households with a male first child are more likely to use clean cooking fuel compared to similar households with a female first child.

${ }^{14}$ Older women were more likely to say that they thought that the chulha was easier to cook on or that both were equally easy to cook on. Some women said that they feared using an LPG stove and cylinder because of fire hazards. There is a case for demonstrating that LPG use can be safe and easy to use through informational campaigns.

${ }^{15}$ To test the significance of attitudes for LPG use, we regress exclusive LPG use on asset wealth and each of the answers to the attitudes questions separately. The $p$-value on believing that gas is at least as easy to cook on compared to chulha is .009 , the $p$-value for food prepared on gas is at least as tasty is .015 , the $p$-value for food prepared on gas is at least as healthy for the eater is .132, and the p-value for preparing food on gas is at least as healthy for person making food is .233 .
} 